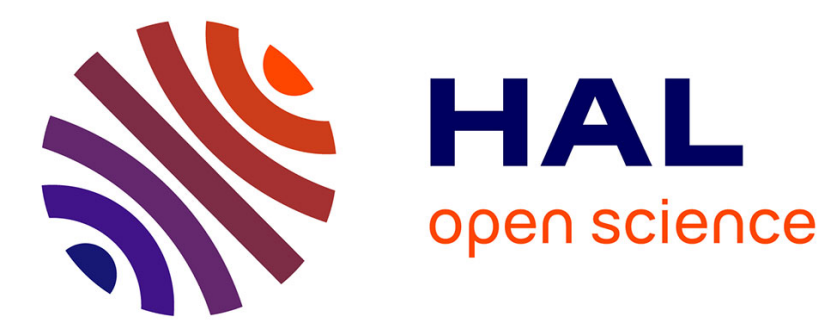

\title{
Low and High-Temperature In Situ X-Ray Absorption Study of the Local Order in Orthorhombic $\alpha$-MoO3 Upon Hydrogen Reduction
}

A. Kuzmin, J. Purans, Ph. Parent, H. Dexpert

\section{To cite this version:}

A. Kuzmin, J. Purans, Ph. Parent, H. Dexpert. Low and High-Temperature In Situ X-Ray Absorption Study of the Local Order in Orthorhombic $\alpha$-MoO3 Upon Hydrogen Reduction. Journal de Physique IV Proceedings, 1997, 7 (C2), pp.C2-891-C2-892. 10.1051/jp4:1997267 · jpa-00255350

HAL Id: jpa-00255350

https://hal.science/jpa-00255350

Submitted on 1 Jan 1997

HAL is a multi-disciplinary open access archive for the deposit and dissemination of scientific research documents, whether they are published or not. The documents may come from teaching and research institutions in France or abroad, or from public or private research centers.
L'archive ouverte pluridisciplinaire HAL, est destinée au dépôt et à la diffusion de documents scientifiques de niveau recherche, publiés ou non, émanant des établissements d'enseignement et de recherche français ou étrangers, des laboratoires publics ou privés. 


\title{
Low and High-Temperature In Situ X-Ray Absorption Study of the Local Order in Orthorhombic $\alpha-\mathrm{MoO}_{3}$ Upon Hydrogen Reduction
}

\author{
A. Kuzmin, J. Purans, Ph. Parent* and H. Dexpert* \\ Institute of Solid State Physics, Kengaraga 8, LV-1063 Riga, Latvia \\ * LURE, Université Paris-Sud, Bât. 209D, 91405 Orsay cedex, France
}

\begin{abstract}
In-situ x-ray absorption spectroscopy has been applied to the study of the modifications of the short range order in orthorhombic $\alpha-\mathrm{MoO}_{3}$ under low and high-temperature hydrogen reduction. It was observed that at low-temperature $(T \approx$ $\left.110^{\circ} \mathrm{C}\right)$ reduction, a formation of molybdenum bronzes $\mathrm{H}_{\mathrm{x}} \mathrm{MoO}_{3}(\mathrm{x} \leq 2)$ occurs while at high-temperature $\left(T \geq 400^{\circ} \mathrm{C}\right)$ reduction, $\alpha-\mathrm{MoO}_{3}$ transforms into $\mathrm{MoO}_{2}$. Both processes have great applied importance since they are related to electrochromic and catalytic properties of $\alpha-\mathrm{MoO}_{3}$. The information on the local atomic and electronic structure, obtained from the Mo K-edge XAFS and XANES analyses, allowed us to follow all steps of the reduction process and to formulate a mechanism of hydrogen interaction with the layered-type structure of $\alpha-\mathrm{MoO}_{3}$.
\end{abstract}

Molybdenum trioxide $\left(\alpha-\mathrm{MoO}_{3}\right)$ has a layer structure built up of distorted $\mathrm{MoO}_{6}$ octahedra which are connected in the $c$-axis direction by corners and edges so as to form zig-zag rows and in the perpendicular $a$-direction only by corners [1]. It is known that the reduction process of $\alpha-\mathrm{MoO}_{3}$ proceeds, depending on the temperature $(T)$ of the reaction, by the following two ways. At low temperature $\left(T \approx 20 \div 100^{\circ} \mathrm{C}\right)$ in the presence of Pt or Pd catalyst, $\alpha-\mathrm{MoO}_{3}$ transfers successively to a series of molybdenum bronzes $\mathrm{H}_{x} \mathrm{MoO}_{3}(\mathrm{x} \leq 2)$ whose topology is close to $\alpha-\mathrm{MoO}_{3}$ with hydrogen atoms being placed at intralayer positions for $\mathrm{x}<0.85$ and at intralayer and interlayer positions for $\mathrm{x}>0.85$ [2]. This low- $T$ reaction has technological applications such as secondary battery electrodes, reversible hydrogen storage cells, electrochromic devices and electrocatalyzers [2]. At high-temperature $\left(T \geq 400^{\circ} \mathrm{C}\right), \alpha-\mathrm{MoO}_{3}$ reduces to $\mathrm{MoO}_{2}$ and further reduction is used to obtain metallic molybdenum of high purity [3]. Note also that high- $T$ reduction of $\alpha-\mathrm{MoO}_{3}$ is of interest because molybdenum (6+) oxide is an important catalyst [3].

In this work, the in-situ X-ray absorption spectra of $\alpha-\mathrm{MoO}_{3}$, reduced by hydrogen, were measured in transmission mode at the Mo K-edge using a setup of the LURE DCI EXAFS-3 beam line. The synchrotron radiation was monochromatized by the $\mathrm{Si}(311)$ double-crystal monochromator and its intensity was measured by two ionization chambers containing argon gas. The low- $T$ measurements were performed at $T=110^{\circ} \mathrm{C}$, while high- $T$ measurements in the temperature range from RT to $400^{\circ} \mathrm{C}$. The details of the experiments and of the data analysis will be published in the forthcoming paper [4].

Upon reduction, the formal valence state of Mo ions decreases from $6+$ to $4+$ leading to the partial filling of the initially empty $4 d(\mathrm{Mo})-2 p(\mathrm{O})$ band and to the significant lowering of the $\mathrm{MoO}_{6}$ octahedra distortion. This conclusion is supported by the decrease of the pre-edge peak in the Mo K-edge XANES (Figure 1) and by the quantitative analysis of the first shell XAFS signal [4]. The symmetrization of the $\mathrm{MoO}_{6}$ octahedra is qualitatively seen in Figure 2 as a decrease of the 1st shell distortion in Fourier transforms of the XAFS signals. Nevertheless, although a tendency of the short-range order modifications is similar, the accurate analysis shows that at high- $T, \alpha-\mathrm{MoO}_{3}$ transforms gradually to rutile-type $\mathrm{MoO}_{2}$ while at low- $T$, a set of phase transitions occurs resulting in $\alpha-\mathrm{H}_{2} \mathrm{MoO}_{3}$ having the structure close to that of the parent oxide. Comparing the FT's of the final products (Figure 2), one can see that the second shell peak at $3.2 \AA$ is higher in $\alpha-\mathrm{H}_{2} \mathrm{MoO}_{3}$ than in $\mathrm{MoO}_{2}$ : this is due to the multiple-scattering effects within 4 nearly linear $\mathrm{Mo}-\mathrm{O}-\mathrm{Mo}$ chains in $\alpha-\mathrm{H}_{2} \mathrm{MoO}_{3}$ (the largest $\mathrm{Mo}-\mathrm{O}-\mathrm{Mo}$ angles in $\mathrm{MoO}$ are only about $144^{\circ}$ ).

Recently it was suggested that the reduction of $\alpha-\mathrm{MoO}_{3}$ to $\mathrm{MoO}_{2}$ is a double-step process: $\alpha-\mathrm{MoO}_{3} \rightarrow \mathrm{Mo}_{4} \mathrm{O}_{11} \rightarrow \mathrm{MoO}_{2}$ [3]. Our results show (Figure 3) that the $\mathrm{Mo}_{4} \mathrm{O}_{11}$ phase was not present during the experiment that agree also with the results of [5]. Moreover, the high- $T$ reduction of $\alpha-\mathrm{MoO}_{3}$ leads to progressive transition from $\alpha-\mathrm{MoO}_{3}$ to $\mathrm{MoO}_{2}$ without presence of any intermediate phase [4]. On the contrary, at low- $T, \alpha-\mathrm{MoO}_{3}$ transforms successively to the series of bronzes $\mathrm{H}_{\mathrm{x}} \mathrm{MoO}_{3}$ accumulating hydrogen ions as $\mathrm{OH}(\mathrm{x}<0.85)$ and/or $\mathrm{OH}_{2}(\mathrm{x}>0.85)$ groups [6] and maintaining general topology of the $\alpha-$ $\mathrm{MoO}_{3}$ lattice. Note also that while in $\alpha-\mathrm{MoO}_{3}$, the peak at $2.3 \AA$ (Figure 2) corresponds mainly to the $\mathrm{Mo} \rightarrow \mathrm{O} \rightarrow \mathrm{O} \rightarrow \mathrm{Mo}$ double-scattering (DS) signal, which is generated within the 1st shell and contains the shortest Mo-O bond (1.66 $\AA$ ), the same peak in $\alpha-\mathrm{H}_{2} \mathrm{MoO}_{3}$ and $\mathrm{MoO}_{2}$ is related to the short $(\sim 2.6 \AA) \mathrm{Mo}-\mathrm{Mo}$ bond (Figure 4) [4]. In the latter case the same DS signal contributes at about $0.4 \AA$ longer distances than in $\alpha-\mathrm{MoO}_{3}$, i.e. at $\sim 2.7 \AA$ in FT shown in Figure 2. 


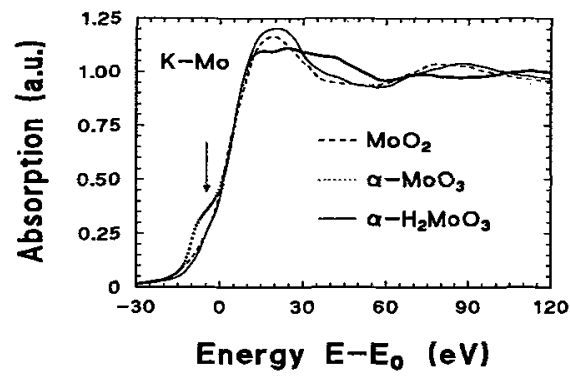

Figure 1: Change of the Mo K-edge XANES upon low- $T$ ( $\alpha$ $\left.\mathrm{MoO}_{3} \rightarrow \alpha-\mathrm{H}_{2} \mathrm{MoO}_{3}\right)$ and high- $T\left(\alpha-\mathrm{MoO}_{3} \rightarrow \mathrm{MoO}_{2}\right)$ reduction. The pre-edge shoulder is marked by arrow.
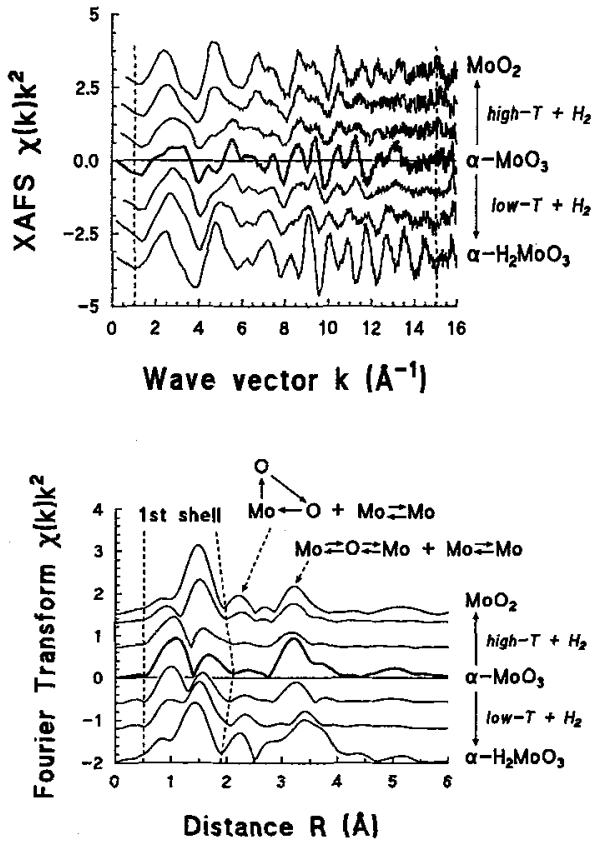

Figure 2: Variation of the experimental XAFS spectra and their FT's upon hydrogen reduction. Only several signals are shown for clarity. The ranges of the FT and the Ist shell back-FT are indicated by dashed lines.

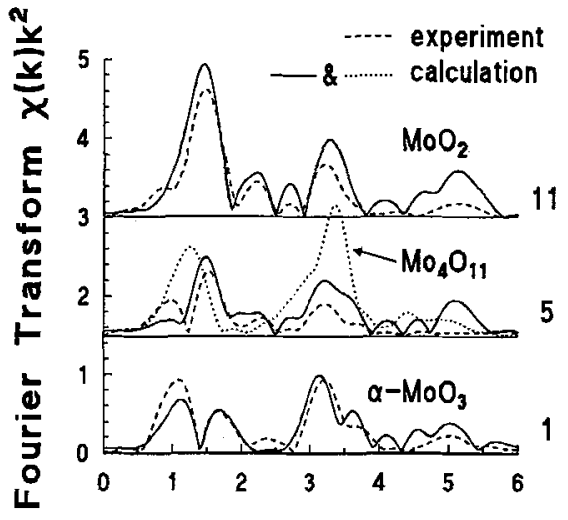

\section{Distance $R(A)$}

Figure 3: FT's of experimental (dotted line) and calculated (solid and dashed lines) XAFS spectra.

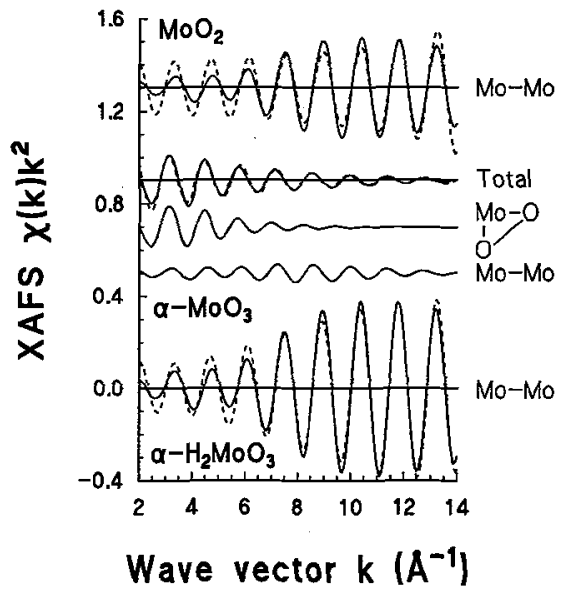

Figure 4: Experimental (dashed lines) and calculated (solid lines) XAFS signals corresponding to the peak at $2.3 \AA$ (see Figure 2).

\section{Acknowledgments}

A.K. and J.P. are grateful to the staff of the LURE DCI EXAFS-3 beam line for the support of the experiments. This work was also supported in part by the International Science Foundation, Grants LF8000 and LJ8100 (A.K. and J.P.).

\section{References}

[1] Kihlborg L., Arkiv Kemi 21 (1963) 357-364.

[2] Ritter Cl., Müller-Warmuth W. and Schöllhorn R, J. Chem. Phys. 83 (1985) 6130-6138.

[3] Sloczynski J., J. Solid State Chem. 118 (1995) 84-92.

[4] Kuzmin A., Purans J., Parent Ph. and Dexpert H. (to be published).

[5] Hansen S. and Andersson A., J. Solid State Chem. 75 (1988) 225-243.

[6] Adams S., Ehses K.-H. and Spilker 1., Acta Cryst. B 49 (1993) 958-967. 